\title{
Factors associated with suicidal behaviors in mainland China: a meta-analysis
}

Ying $\mathrm{Li}^{1}$, Yafei $\mathrm{Li}^{2}$ and Jia $\mathrm{CaO}^{3^{*}}$

\begin{abstract}
Background: Suicide is a major public health issue in China. Studies of suicide risk factors have reported both inconsistent and inconclusive results. This review aimed to determine suicide risk factors in China.

Methods: Medline/PubMed, EMBASE, CNKI (China National Knowledge Infrastructure) and VIP (Chinese Journal of Science and Technology of VIP) were searched for relevant reports. Two investigators independently assessed the eligibility of identified studies and extracted data. Pooled odds ratios (and 95\% confidence intervals) were calculated for each factor with Revman 5.0.

Results: Forty-four studies with 192,362 subjects were included. The pooled results indicated that mood disorders and stressful life events (physical illness, suicide of relatives) increased the risk of suicide ideation among the entire population. Socio-family environment (single or remarried parent, study pressure and academic achievement) and unhealthy behaviors (smoking, alcohol drinking, and drug use) were risk factors for suicide ideation among youth. Unhealthy behaviors (smoking and alcohol drinking), mood disorders, and stressful life events (suicide of relatives) were the main risk factors for attempted suicide. Persons living in rural areas, and those with lower education, mood disorders, and/or a history of negative life events had a higher risk of completed suicide. In China, before 2000, females had a significantly higher rate of completed suicide than males, while after 2000, no significant gender difference was found.

Conclusions: Socio-family environment, lifestyle, life events and psychiatric/psychological factors are associated with suicidal behaviors in China. Further case-control or cohort studies are needed to better understand suicide behaviors in China. Meanwhile, there is an urgent need for comprehensive studies of suicide interventions among high-risk populations.
\end{abstract}

Keywords: Risk factors, Suicide, China, Meta-analysis

\section{Background}

Suicide is an important global public health problem. According to the World Health Organization (WHO), approximately one million people committed suicide, and 10-20 times that number attempted suicide worldwide in 2000 [1]. Globally, suicide is one of the three leading causes of death among people aged 15-34 years [2] and suicide rates have increased by $60 \%$ over the last 45 years [3]. Reducing mortality and morbidity associated with suicidal behavior is high on the WHO agenda [3].

\footnotetext{
*Correspondence: caojia1962@126.com

${ }^{3}$ College of Preventive Medicine, Key Lab of Medical Protection for Electromagnetic Radiation, Ministry of Education of China, Third Military Medical University, No.30 Gaotanyan Road, Shapingba District, Chongqing, People's Republic of China

Full list of author information is available at the end of the article
}

China has long been recognized as having a high suicide rate, with 21 percent of the world's population, but 30-40 percent of the world's suicides [4]. Suicide patterns in China are different from those in the West. Previously in China, females had consistently higher suicide rates than males [5]. However, in recent years, this pattern has reversed. In 2008, the national male suicide rate $(7.0 / 100,000)$ was higher than the national female suicide rate $(6.20 / 100,000)$, as was the rural male suicide rate ( 4.0 vs. $3.18 / 100,000$, respectively) and the urban male suicide rate (8.62 vs. $7.87 / 100,000$, respectively) [5]. The suicide rate in China has substantially decreased over the last 20 years, with the 2008 national suicide rate being approximately 63 percent lower than the 1987 rate (17.65 vs. $6.60 / 100,00$, respectively).

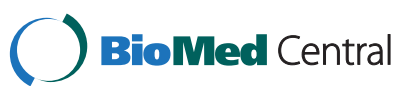


Despite the decreased national suicide rate, suicide is still threatening the health of youth and elderly in China. An understanding of the risk factors is imperative for effective suicide prevention. Suicide risk factors have attracted a great deal of research attention in China. Many studies have investigated the influence of demographic, socio-psychological, economic and lifestyle-related factors, and physical illness on suicidal behavior. However, the results of these studies have been inconsistent. For example, some studies found that females had a higher suicide risk than males [6,7], while others found no significant differences in risk between the sexes $[8,9]$. In addition, some studies $[10,12]$ found no significant association between family type and suicide ideation, while others found that belonging to a remarried [13] or single parent [17] family increased the risk of forming suicide ideation.

This meta-analysis aimed to comprehensively examine the risk factors of completed suicide and suicidality (suicide ideation and suicide attempt) in the Chinese population. From our findings, we were able to draw a series of recommendations for future intervention programs and studies.

\section{Methods}

\section{Search strategy}

Electronic database and manual searches were conducted to identify published articles for review. Four databases were used to search for articles published up to January, 2011: Medline/PubMed, EMBASE, CNKI (China National Knowledge Infrastructure) and VIP (Chinese Journal of Science and Technology of VIP). The searches applied a mixture of free text and index terms. The search terms in PubMed were ("Suicide"[Mesh] AND "Risk Factors"[Mesh]) AND "China"[Mesh], ("Suicide"[Mesh] AND "China"[Mesh], (("Risk Factors"[Mesh]) AND "Suicidal Ideation"[Mesh]) AND "China"[Mesh], (("Risk Factors"[Mesh]) AND "Suicide, Attempted"[Mesh]) AND "China"[Mesh], risk factor for suicide in China, suicide in China. The results in Medline/ PubMed were limited to full text, human, English and Chinese. The EMTREE search in EMBASE was 'suicide'/exp AND 'risk factor'/exp AND 'china'/exp, 'suicide'/exp AND 'china'/exp, 'risk factor'/exp AND 'suicidal ideation'/exp AND 'China'/exp, 'risk factor'/exp AND 'suicide attempt'/exp AND 'China'/exp. All results in EMBASE were limited to English, human. CNKI and VIP were used to search for articles in Chinese, and the subject words included risk factors for suicide, risk factors for suicide ideation, and risk factors for attempted suicide. We reviewed the references cited in the retrieved articles and then searched the bibliographies of these retrieved papers.

\section{Selection of studies}

Studied design included cross-sectional, case-control, and cohort studies. Study subjects were from the general population of mainland China. Suicidal behavior outcomes included suicide ideation (thoughts of engaging in behavior intended to end one's life), suicide attempt (engagement in potentially self-injurious behavior in which there is at least some intent to die), and completed suicide (the act of intentionally ending one's life). We also included the studies that were designed with the original purpose of analyzing risk behaviors other than suicide among Chinese people, but the information on the risk factors for suicide ideation, suicide attempt or completed suicide were provided. Studies that focused on subjects from Hong Kong or Taiwan, that investigated psychopathic suicide, that repeated data reported in earlier studies, or that were systematic reviews or meta-analyses were excluded from our analysis.

\section{Validity assessment}

To determine the validity of the research, the quality of each case-control study was assessed by the second author according to the primary criteria for nonrandomized studies described in the Newcastle-Ottawa Scale (NOS) [14] as follows: A. selection of the study groups; B. comparability of the groups; C. ascertainment of the exposure. For crosssectional studies, we evaluated four aspects of the quality of the studies: A. representativeness of study participants, B. proper methods to ascertain exposure, C. comparability of the analysis groups, and D. low non-response bias. Each study was scored with respect to meeting (1) or not meeting (0) each of these criteria, and a dash indicated that fulfillment of the criteria could not be determined.

\section{Data abstraction}

All of the identified articles about suicide among Chinese subjects were examined in detail. Two reviewers independently abstracted the data from potentially relevant articles. Differences were resolved by consensus. For crosssectional studies, sampling strategy, sample size, characteristics of participants, and information used for comparative analyses were abstracted. For case-control studies, information about the size of the case and control groups; characteristics of participants; and the number of cases/controls exposed and not exposed to the study factors were abstracted from each study. When the results of a study were published more than once, only the most complete data were included in our analysis.

\section{Assessment of heterogeneity}

We evaluated heterogeneity between the studies using the $\mathrm{Q}$ test $[15]$ and the I-squared statistic $\left(\mathrm{I}^{2}=100 \% \times(\mathrm{Q}-\mathrm{df}) / \mathrm{Q}\right)$ [16]. For the $\mathrm{Q}$ test, a $P$ value of less than 0.10 was considered statistically significant. If $P>0.10$, there was a lack of heterogeneity between the studies. If $P \leq 0.10$ (i.e., heterogeneity was significant), we calculated $\mathrm{I}^{2}$. If $\mathrm{I}^{2} \leq 50 \%$, the heterogeneity might be acceptable; otherwise, there was significant heterogeneity between studies and we conducted 
a subgroup analysis. For the subgroup analyses, heterogeneity within groups was also tested.

\section{Data synthesis}

The classification of suicide risk factors is somewhat arbitrary in current reports. To better describe and sort the risk factors, we classified them in the text as follows: demographic factors, socio-family environment, lifestyle/ behaviors, negative/stressful life events and psychiatric/ psychological factors. To estimate the associations between these factors and suicide, we calculated pooled odds ratios (OR) for suicide ideation, suicide attempt, and completed suicide separately, using RevMan 5.0 software (RevMan software, Version 5.0, Cochrane Collaboration, Oxford, United Kingdom). If there was no significant heterogeneity
( $P>0.10$ or $P \leq 0.10$, but $\mathrm{I}^{2}<50 \%$ ), a fixed effects model was used to pool the data. If significant heterogeneity $\left(P \leq 0.10, \mathrm{I}^{2}>50 \%\right)$ was found between studies, the metaanalysis was conducted using a random effects model. Subgroup analyses were performed to explore possible reasons for the heterogeneity.

\section{Results}

\section{Description of studies}

A detailed diagram of the full review process is presented in Figure 1. We identified 1101 potentially relevant articles. After reviewing their titles, abstracts, and full text, 43 studies]. (Table 1) with 192,362 subjects had suitable data for meta-analysis and were therefore included in our study (39 cross-sectional studies and 4 case-control studies).

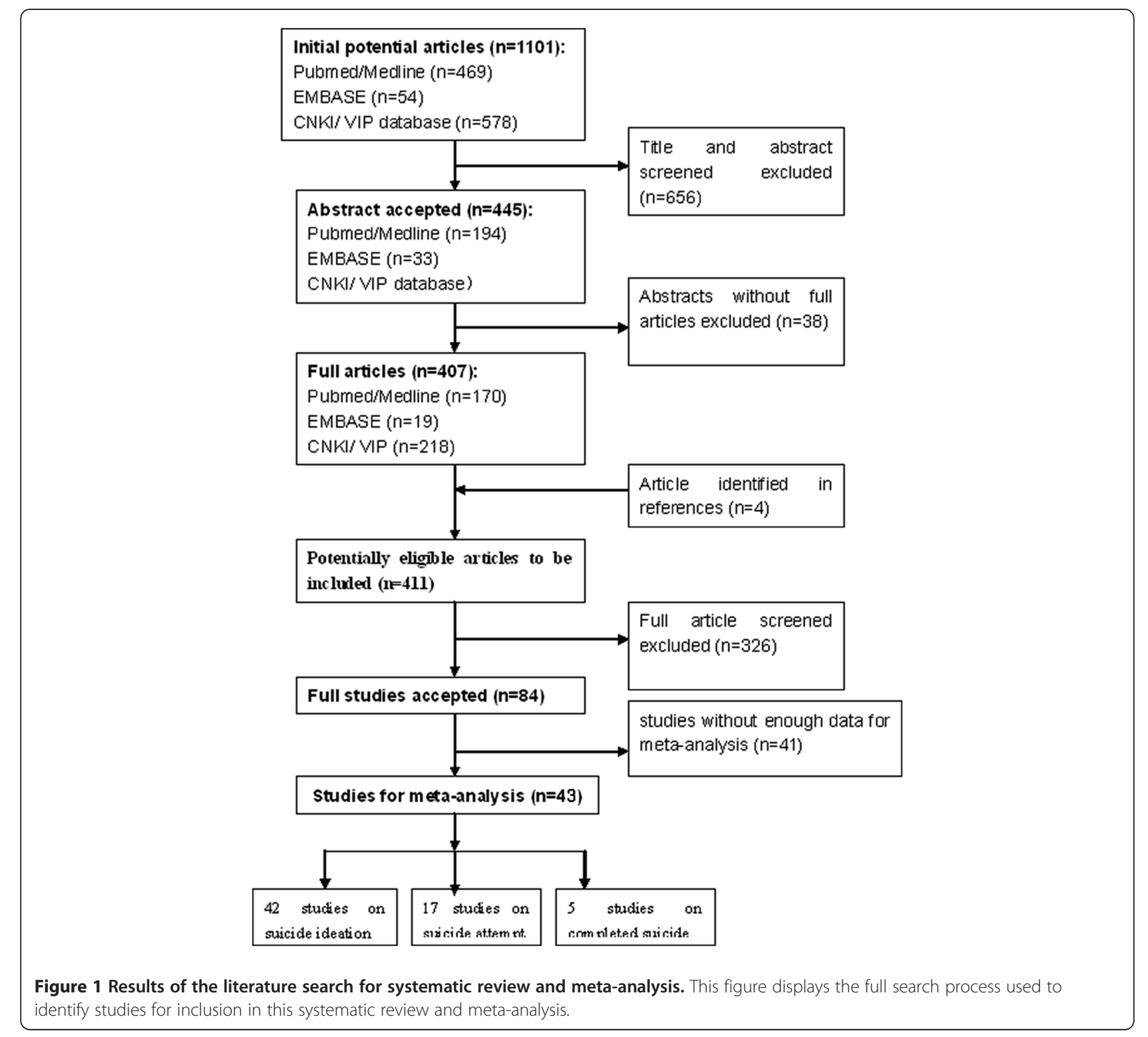


Table 1 Descriptive information for each study included in meta-analysis $※$

\begin{tabular}{|c|c|c|c|c|c|c|c|}
\hline Studies & $\begin{array}{l}\text { Study } \\
\text { type }\end{array}$ & $\begin{array}{l}\text { Sampling } \\
\text { size }\end{array}$ & Study population & Gender & Residence & $\begin{array}{l}\text { Years of data } \\
\text { collection }\end{array}$ & Outcome \\
\hline Zhang 1999[6] & CS & 84767 & $16-78$ years old & Female/male & Rural/urban & 1989-1994 & Complete suicide \\
\hline Kong 2010[7] & $\mathrm{CC}$ & $370 / 370$ & $\begin{array}{l}\text { The suicides }(45.30 \pm 12.88) / \\
\text { living } \\
\text { controls }(35.03 \pm 12.6)\end{array}$ & Female/male & Rural & 2005-2008 & Complete suicide \\
\hline Phillips 2002[8] & $\mathrm{CC}$ & $519 / 536$ & $\begin{array}{l}\text { The suicides/other injuries } \\
\qquad>10 \text { years) }\end{array}$ & Female/male & Rural/urban & $1998-2000$ & Complete suicide \\
\hline Li 2005[9] & CS & 1653 & Adolescents & Female/male & Rural/urban & 1995-1999 & Complete suicide \\
\hline Zhang 2003[10] & CS & 1421 & Adolescents & Male/female & - & - & Suicide ideation \\
\hline Liu 2007[12] & CS & 1933 & Adolescents & Male/female & Rural/urban & - & Suicide ideation \\
\hline Ou 2008[13] & CS & 698 & College Students & Male/female & Rural/urban & 2005 & Suicide ideation \\
\hline Ma 2003[17] & CS & 853 & Adolescents & Male/female & Urban & - & Suicide ideation \\
\hline Fan 2008[18] & CS & 2160 & College Students & Male/female & Rural/urban & - & Suicide ideation \\
\hline Zhang 2007[11] & CS & 1294 & Adolescents & Male/female & Urban & - & Suicide ideation \\
\hline Zeng 2005[19] & CS & 427 & College Students & Male/female & Rural/urban & 2003 & Suicide ideation \\
\hline Li 2009[20] & $C Y$ & 2,012 & $\begin{array}{l}\text { Community members } \\
\text { (>18 years) }\end{array}$ & Male/female & Rural/urban & 2004 & Suicide ideation \\
\hline Yang 2008[21] & CS & 8315 & Adolescents & Male/female & Rural & 2006 & $\begin{array}{l}\text { Suicide ideation, } \\
\text { suicide attempt }\end{array}$ \\
\hline Pan 2006[22] & CS & 5169 & Adolescents & Male/female & Rural/urban & 2004 & Suicide ideation \\
\hline Chen 2006[23] & CS & 7422 & College Students & Male/female & Rural/urban & - & Suicide ideation \\
\hline Yang 2007[24] & CS & 3568 & College Students & Male/female & Rural/urban & 2006 & Suicide ideation \\
\hline Duan 2008[25] & CS & 5,640 & $\begin{array}{l}\text { Community members } \\
\text { (32-64 years) }\end{array}$ & Male/female & - & - & $\begin{array}{c}\text { Suicide ideation, Suicide } \\
\text { attempt }\end{array}$ \\
\hline Hou 2010[26] & CS & 239 & $\begin{array}{l}\text { Suicide-attempt } \\
\text { cases }(>15 \text { years })\end{array}$ & Male/female & - & $2007-2008$ & Suicide ideation \\
\hline Sun 2010[27] & CS & 20716 & $\begin{array}{c}\text { Community members, } \\
>18 \text { years }\end{array}$ & Male/female & Rural/urban & 2004-2005 & Suicide attempt \\
\hline Bao 2009[28] & $\mathrm{CS}$ & 1529 & College Students & Male/female & Rural/urban & - & Suicide ideation \\
\hline Juan 2010[29] & CS & 4644 & Adolescents & Male/female & Urban & 2004 & $\begin{array}{c}\text { Suicide ideation, suicide } \\
\text { attempt }\end{array}$ \\
\hline Niu 2006[30] & CS & 2,914 & $\begin{array}{l}\text { Patients without psychopathic } \\
\text { problem in hospital ( }>15 \text { years) }\end{array}$ & Male/female & Rural/urban & 2003-2004 & $\begin{array}{c}\text { Suicide ideation, suicide } \\
\text { attempt }\end{array}$ \\
\hline Tian 2010[31] & CS & 974 & Researcher(34 \pm 8$)$ & Male/female & - & - & Suicide ideation \\
\hline Sun 2008[32] & CS & 943 & Migrants & Male/female & - & - & $\begin{array}{c}\text { Suicide ideation, suicide } \\
\text { attempt }\end{array}$ \\
\hline Li 2004[33] & CS & 2032 & Students in technical school & Male/female & Rural/urban & - & Suicide attempt \\
\hline Yu 2004[34] & CS & 1952 & Adolescents & Male/female & Rural & - & $\begin{array}{c}\text { Suicide ideation, suicide } \\
\text { attempt }\end{array}$ \\
\hline Xing 2005[35] & CS & 4622 & Adolescents & Male/female & - & 2002 & Suicide ideation \\
\hline Gao 2001[36] & CS & 2044 & Adolescents & Male/female & Rural/urban & 1998 & $\begin{array}{c}\text { Suicide ideation, suicide } \\
\text { attempt }\end{array}$ \\
\hline Zhuang 2007[37] & $\mathrm{CS}$ & 3798 & Adolescents & Male/female & urban & - & $\begin{array}{c}\text { Suicide ideation, suicide } \\
\text { attempt }\end{array}$ \\
\hline Huang 2000[38] & CS & 2467 & Adolescents & Male/female & - & - & Suicide ideation \\
\hline Zeng 2009[39] & CS & 490 & College Students & Male/female & Rural/urban & - & Suicide ideation \\
\hline Yan 2009[40] & CS & 772 & College Students & Male/female & - & After 2007 & Suicide ideation \\
\hline Shang 2008[41] & CS & 2678 & College Students & Male/female & Rural/urban & 2006 & $\begin{array}{c}\text { Suicide ideation, suicide } \\
\text { attempt }\end{array}$ \\
\hline Lin 2005[42] & CS & 1100 & College Students & Male/female & - & - & Suicide ideation \\
\hline
\end{tabular}


Table 1 Descriptive information for each study included in meta-analysis $※$ (Continued)

\begin{tabular}{|c|c|c|c|c|c|c|c|}
\hline Zhu 2006[43] & CS & 1765 & College Students & Male/female & - & 2004 & Suicide ideation \\
\hline Xu 2004[44] & CS & 610 & College Students & Male/female & Rural/urban & - & Suicide ideation \\
\hline Zhou 2005[45] & CS & 337 & Adolescents & Male/female & Rural & 2004 & Suicide ideation \\
\hline Jiang 2006[46] & CS & 1514 & Adolescents & Male/female & Rural/urban & - & Suicide ideation \\
\hline Zhang 2009[47] & CS & 15,000 & residents, & Male/female & Rural & 2001 & Suicide ideation \\
\hline Feng 2006[48] & CS & 2584 & Adolescents & Male/female & urban & 2004 & $\begin{array}{c}\text { Suicide ideation, suicide } \\
\text { attempt }\end{array}$ \\
\hline Sun 2007[49] & CS & 1,021 & Rural female(15-39 years) & female & Rural & - & Suicide ideation \\
\hline Huan 2004[50] & $\mathrm{CC}$ & $100 / 100$ & $\begin{array}{l}\text { Suicide-attempt cases/injured } \\
\text { by accidents }\end{array}$ & Male/female & Rural/urban & 2002 & Suicide attempt \\
\hline Yang 2008[51] & $\mathrm{CC}$ & $22 / 23$ & $\begin{array}{c}\text { The suicide( } 43.1 \text { years)/other } \\
\text { injuries( } 48.2 \text { years) }\end{array}$ & Female/male & Rural & 1998-1999 & Complete suicide \\
\hline
\end{tabular}

※: CC refers to case-control study; CS refers to cross-sectional study.

The methodological characteristics of the included studies were then evaluated. In most of the cross-sectional studies, the participants had good representativeness. However, 7 cross-sectional studies $[13,19,23,26,34,38,42]$ had no description of sampling methods or a small sample size. The exposure and control groups in the majority of studies were comparable, except for three studies $[21,34,35]$ that did not compare them and seven studies [11,17,22,36-39] that did not report the non-response rate. Overall, only 3 studies $[34,38,39]$ scored below 3 (Additional file 1: Table S1). All case-control studies scored six or above and were judged as being of high methodological quality (Additional file 1: Table S2).

\section{Meta-analysis}

There were 42, 17, and 5 studies with dichotomous data available for a meta-analysis of the factors associated with suicide ideation, suicide attempt and completed suicide, respectively. Heterogeneity tests were carried out on all of these studies and the results are presented in Table 2.

In terms of suicide ideation, significant heterogeneity was found for studies of the association of suicide ideation with gender, education, residence, mood disorders, physical health, suicide of relatives, and the economy. The pooled ORs and 95\% CIs indicated that demographic factors (female gender), psychiatric/psychological factors (mood disorders) and negative/stressful life events (poor physical health, suicide of relative) were risk factors for suicide ideation among the Chinese population [pooled OR (95\% CI): 1.43 (1.25, 1.64), $5.12(3.78,6.94), 4.88(1.24,18.68)$ and 3.02 (1.81, 5.04), respectively]. Lifestyle/behaviors (smoking, alcohol drinking, and substance use), family environment (single or remarried parent), poor academic achievement and study pressure were significant risk factors for suicide ideation among youth (adolescents and college students) [pooled OR (95\% CI): 1.67 (1.45, 1.92), 1.96 (1.69, 2.27), 1.55 (1.23, 1.96), $1.97(1.39,2.80), 1.25(1.08,1.44)$ and $1.27(1.17,1.38)$, respectively] (Table 2 and Figure 2).
The factors associated with suicide attempt are shown in Table 2 and Figure 3. Heterogeneity tests identified significant heterogeneity among studies of the association of suicide attempt with gender, education, residence and mood disorders. Results of the meta-analysis showed that psychiatric/psychological factors (mood disorders), socio-family environment (poor relationship with family), lifestyle/behaviors (smoking, alcohol use) and negative life events (suicide of relatives) were significantly associated with attempted suicide [pooled OR (95\% CI): 3.44 (1.93, 6.14), 3.64 (2.97, 4.47), 1.79 (1.36, 2.35), 2.50 (1.86, 3.36), 4.80 (3.12, 7.39), respectively].

Heterogeneity tests showed that studies of the association between mood disorders, seeking help for mood disorders, previous suicide attempt, suicide of relatives, negative life events, pesticides stored at home and completed suicide lacked significant heterogeneity. According to the pooled ORs and 95\% CIs, demographic factors (female gender, residence in rural area, lower education), psychiatric/ psychological factors (mood disorder), negative life events and recent change in life predicted completed suicide [pooled OR (95\% CI): 2.35 (1.15, 4.78), 2.86 (1.20, 6.84), 2.33 (1.48, 3.66), 30.54 (20.46, 45.58), 10.03 (6.63, 15.19), and $3.79(2.56,5.61)$, respectively](Table 2 and Figure 4$)$.

\section{Subgroup analysis}

Given the available collected data, we conducted subgroup analyses of both suicide ideation and completed suicide. Many studies have investigated the factors associated with suicide ideation among youth (adolescents and college students). We carried out subgroup analyses of the association of suicide ideation with gender, mood disorders, physical health, and suicide of relatives by population, namely, youth vs. the rest of the population. The heterogeneity test showed that studies of the effects of physical illness $[13,28,39]$ and suicide of relatives $[9,11]$ on youth suicide ideation lacked heterogeneity, but studies on the effect of gender and mood disorder had significant heterogeneity 
Table 2 Results of meta-analysis of the studies on association between factors and suicide in Chinese population

\begin{tabular}{|c|c|c|c|c|c|c|c|}
\hline \multirow[t]{2}{*}{ Factors } & \multirow{2}{*}{$\begin{array}{l}\text { No. of } \\
\text { studies }\end{array}$} & \multirow{2}{*}{$\begin{array}{c}\text { No. of } \\
\text { participants }\end{array}$} & \multicolumn{2}{|c|}{ Variance between studies } & \multirow{2}{*}{$\begin{array}{l}\text { Pooled } \\
\text { OR }\end{array}$} & \multirow[t]{2}{*}{$95 \% \mathrm{Cl}$} & \multirow{2}{*}{$\begin{array}{l}\text { Test for } \\
\text { overall } \\
\text { effect }(p)\end{array}$} \\
\hline & & & $\mathrm{Q}(p)$ & $I^{2}(\%)$ & & & \\
\hline \multicolumn{8}{|l|}{ Suicide ideation } \\
\hline \multicolumn{8}{|l|}{ Demographic characteristics } \\
\hline Gender (female) & 27 & 71546 & $<0.00001$ & 88 & 1.43 & $1.25,1.64$ & $<0.00001^{*}$ \\
\hline Rural residence & 15 & 51850 & $<0.00001$ & 78 & 0.99 & $0.87,1.12$ & $0.85 *$ \\
\hline Lower education & 9 & 33749 & $<0.00001$ & 95 & 1.39 & $0.91,2.13$ & $0.13^{*}$ \\
\hline Poor economy & 8 & 13260 & 0.004 & 66 & 1.16 & $0.91,1.49$ & $0.24 *$ \\
\hline \multicolumn{8}{|l|}{ Psychiatric or psychological factors } \\
\hline Mood disorder & 6 & 15842 & $<0.00001$ & 86 & 5.12 & $3.78,6.94$ & $<0.00001^{\circledast}$ \\
\hline \multicolumn{8}{|l|}{ Socio-family environment } \\
\hline "Special family & 8 & 11490 & 0.07 & 46 & 1.55 & $1.23,1.96$ & $<0.00001^{*}$ \\
\hline One child in family & 11 & 23486 & 0.04 & 47 & 1.04 & $0.96,1.13$ & $0.33^{\star}$ \\
\hline Poor relationship with families & 2 & 2345 & 0.25 & 26 & 2.31 & $1.53,3.54$ & $0.0001^{\star}$ \\
\hline Poor academic achievement & 6 & 9354 & 0.44 & 0 & 1.25 & $1.08,1.44$ & $0.003^{\star}$ \\
\hline Study pressure & 3 & 12590 & 0.16 & 46 & 1.27 & $1.17,1.38$ & $<0.00001 *$ \\
\hline \multicolumn{8}{|l|}{ Lifestyle/Behaviors } \\
\hline Smoking & 4 & 9197 & 0.21 & 34 & 1.67 & $1.45,1.92$ & $<0.00001^{\star}$ \\
\hline Alcohol & 4 & 10437 & 0.17 & 41 & 1.96 & $1.69,2.27$ & $<0.00001^{\star}$ \\
\hline Drug use & 3 & 5280 & 0.37 & 0 & 1.97 & $1.39,2.80$ & $0.0001^{\star}$ \\
\hline \multicolumn{8}{|l|}{ Stressful life events } \\
\hline Physical illness & 9 & 22639 & $<0.00001$ & 98 & 4.82 & $1.24,18.68$ & $0.01^{*}$ \\
\hline Suicide of relatives & 4 & 14163 & 0.002 & 80 & 3.02 & $1.81,5.04$ & $<0.0001^{\star}$ \\
\hline \multicolumn{8}{|l|}{ Suicide attempt } \\
\hline \multicolumn{8}{|l|}{ Demographic characteristics } \\
\hline Gender (female) & 13 & 3462 & $<0.00001$ & 79 & 1.09 & $0.80,1.50$ & $0.59 *$ \\
\hline rural residence & 7 & 12006 & 0.004 & 69 & 0.78 & $0.53,1.15$ & $0.21^{*}$ \\
\hline Currently unmarried & 5 & 24938 & 0.06 & 60 & 1.19 & $0.88,1.60$ & $0.27^{\star}$ \\
\hline Lower education & 2 & 2954 & 0.05 & 75 & 1.24 & $0.80,1.90$ & $0.34^{*}$ \\
\hline \multicolumn{8}{|l|}{ Psychiatric or psychological factors } \\
\hline Mood disorder & 4 & 19277 & $<0.00001$ & 88 & 2.74 & $1.31,5.74$ & 0.007 \\
\hline \multicolumn{8}{|l|}{ Socio-family environment } \\
\hline Poor relationship with families & 4 & 15371 & 0.15 & 43 & 3.64 & $2.97,4.47$ & $<0.00001^{\star}$ \\
\hline One child in family & 2 & 3100 & 0.69 & 0 & 1.77 & $1.26,2.49$ & $0.001^{\star}$ \\
\hline \multicolumn{8}{|l|}{ Lifestyle/Behaviors } \\
\hline Smoking & 4 & 7995 & 0.18 & 39 & 1.79 & $1.36,2.35$ & $<0.0001^{\star}$ \\
\hline Alcohol use & 3 & 7798 & 0.37 & 0 & 2.50 & $1.86,3.36$ & $<0.00001^{\star}$ \\
\hline Drug use & 2 & 5889 & 0.23 & 30 & 7.33 & $4.60,11.67$ & $<0.00001^{\star}$ \\
\hline \multicolumn{8}{|l|}{ Stressful life events } \\
\hline Poor physical health & 4 & 8685 & 0.04 & 65 & 2.44 & $0.93,6.41$ & $0.07^{\star}$ \\
\hline Suicide of relatives & 3 & 13016 & 0.97 & 0 & 4.80 & $3.12,7.39$ & $<0.00001^{\star}$ \\
\hline \multicolumn{8}{|l|}{ Completed suicide } \\
\hline \multicolumn{8}{|l|}{ Demographic characteristics } \\
\hline Gender (female) & 4 & 397382 & $<0.01$ & 73 & 2.35 & 1. $15,4.78$ & $0.02 \%$ \\
\hline Lower education & 4 & 398072 & 0.003 & 79 & 2.33 & $1.48,3.66$ & $0.0003^{※}$ \\
\hline
\end{tabular}


Table 2 Results of meta-analysis of the studies on association between factors and suicide in Chinese population (Continued)

\begin{tabular}{|c|c|c|c|c|c|c|c|}
\hline$\overline{\text { Residence(rural) }}$ & 3 & 397337 & 0.04 & 69 & 2.86 & $1.20,6.84$ & $0.02^{※}$ \\
\hline Currently married & 6 & 398710 & $<0.00001$ & 96 & 1.14 & $0.50,2.60$ & $0.76^{*}$ \\
\hline \multicolumn{8}{|l|}{ Psychiatric or psychological factors } \\
\hline Mood disorder & 4 & 1757 & 0.9 & 0 & 30.54 & $20.46,45.58$ & $<0.00001^{\star}$ \\
\hline \multicolumn{8}{|l|}{ Stressful life events } \\
\hline Negative life event & 3 & 1264 & 0.63 & 0 & 10.03 & $6.63,15.19$ & $<0.00001^{\star}$ \\
\hline Seeking help for mood disorder & 2 & 1215 & 1.00 & 0 & 5.41 & $3.36,8.71$ & $<0.00001^{\star}$ \\
\hline Previous suicide attempt & 2 & 1306 & 0.68 & 0 & 31.77 & $13.48,74.91$ & $<0.00001^{\star}$ \\
\hline Suicide of relatives & 2 & 1218 & 0.79 & 0 & 4.55 & $3.03,6.85$ & $<0.00001^{\star}$ \\
\hline Pesticides stored at home & 2 & 1543 & 0.60 & 0 & 1.92 & $1.55,2.37$ & $<0.00001 *$ \\
\hline Change of life & 3 & 1231 & 0.86 & 0 & 3.79 & $2.56,5.61$ & $<0.00001$ \\
\hline
\end{tabular}

"Special family included reconstituted family, single-parent family, or non-parent family.

${ }^{\star}$ Pooled data by a fixed effect model.

※pooled data by a random effect model.

$(P<0.00001)$. For factors associated with suicide ideation in the rest of the population, studies lacked heterogeneity, except for those of physical illness $(P<0.00001)$ [28-32]. The pooled ORs (and 95\% CIs) showed that female gender, mood disorders, physical illness, and suicide of relatives were still risk factors for youth suicide ideation [pooled OR (95\% CI): 1.36 (1.18, 1.56), 4.97 (3.37, 7.34), 2.92 (1.39, 6.12) and 1.97 (1.44, 2.68), respectively] (Figure 5).

For the factors associated with completed suicide, the subgroup analyses were performed by year of data collection. Regarding gender and completed suicide, when we excluded study data collected after 2000 [6], the studies using data collected before 2000 still had significant heterogeneity. The pooled results indicated that females had an even higher risk of completed suicide than males [pooled OR $(95 \%$ CI): $3.03(1.75,5.23)]$. As for education and completed suicide, when we excluded study data collected after 2000 [7], the studies [7,8] using data collected before 2000 lacked heterogeneity. The pooled OR still indicated that lower education was a risk factor for completed suicide in China [pooled OR (95\% CI): 1.95 (1.57, 2.44)] (Figure 6).

\section{Discussion}

In recent years, much attention has been given to suicide prevention in China. Since 1999, suicide prevention has been listed as a mental health priority of the Ministry of Health in China [33]. We systematically reviewed a range of risk factors of suicidal behaviors in China. Given that there is a large body of literature on the associations between numerous factors and suicidal behaviors, our meta-analysis only provides a review of the strongest and most consistently reported factors.

In Western countries, males have a higher risk of completed suicide than females [52]. In China, based on the studies included in our meta-analysis, the opposite pattern was identified; females had a 2.35 -fold higher risk of completed suicide than males. In the subgroup analysis, when we excluded the study [7] with data covering 2005-2008, the pooled results of studies with pre2000 data indicated that women had an even higher risk (3.03-fold) of suicide, which hinted that the impact of gender on suicide in China is gradually decreasing. This result is consistent with that of Zhang et al. [5], who found that the female suicide rate decreased more than the male suicide rate during the period between 1987 and -2008 (20.4 to $6.2 / 100,000$ vs. 14.9 to $7.0 / 100,000$, respectively) [5], which is due to the economic development over the past decades resulting in increase of female social status in China, particularly in rural areas [5]. Our meta-analysis indicated that people living in rural areas and those with less education have a higher risk of completed suicide (pooled $\mathrm{OR}=2.86$ and 2.33, respectively). These results may explain the high suicide rates in rural areas of China [5].

Socio-family environmental factors, such as personal relationships, family violence, social and family conflicts and a sense of isolation, were significantly associated with a higher risk of completed suicide [52-56]. Previous reviews also report that multiple social and interpersonal factors, such as parent/family and peer relationships, are important for our understanding of adolescent suicidality [57]. The present meta-analysis also indicated that being in a special family (single or remarried parent), poor academic achievement and study pressure increase the risk of developing suicide ideation among adolescents and college students (pooled $\mathrm{OR}=1.50,1.25$ and 1.27, respectively). These factors may influence the development of personality or psychological disorders among youth and adolescents [58]. Our results highlight the importance of establishing harmonious family and social environments for 


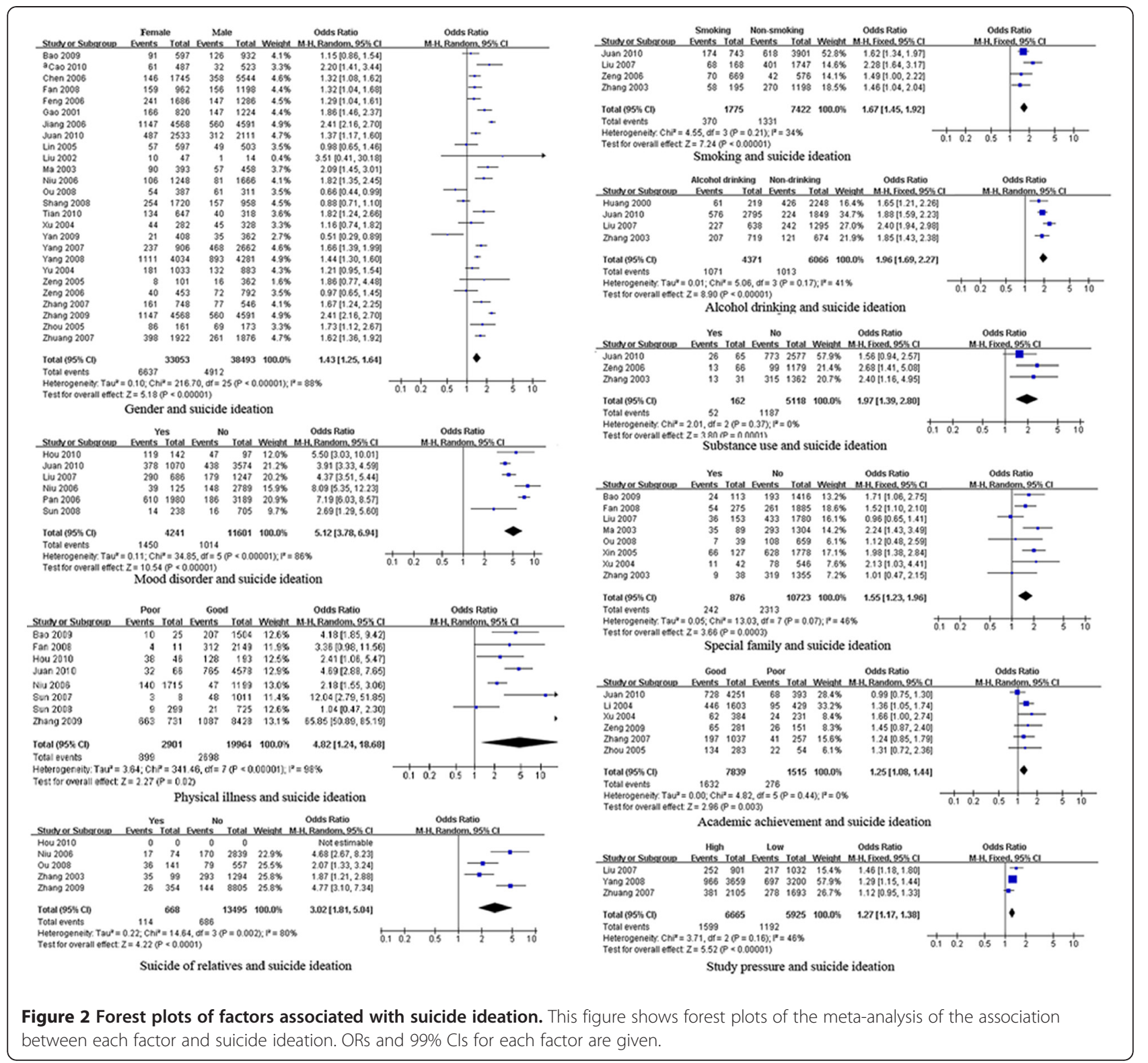

suicide prevention. School factors should also be considered for student suicide prevention.

As for the psychiatric/psychological factors, it has been reported that mental disorders, mood disorders (severe depression, anxiety, sadness, and so on), and personality disorders are major risk factors for suicidality worldwide, particularly in Western countries [52,55,57,59-61]. However, Zhang et al. pointed out that in China, although still important, psychiatric factors are not the main factors associated with suicide [5]. Our meta-analysis similarly found that people with a mood disorder had 2.48-, 3.44- and 20.31-fold higher risk of suicide ideation, suicide attempt and completed suicide in China, respectively. However, the included studies qualitatively described psychiatric/ psychological factors using with/without sadness, depression, and despair, rather than quantitatively measured it with a standard instruments, which may result in different criteria implemented in different studies to decide with or without these mood disorders. Therefore, a standard scale in the future studies is needed for measuring mood disorders in order to compare between studies.

Negative/stressful life events influence health in many respects. Previous studies have reported that stressful life events are associated with suicide. For example, poor physical health, disabilities, history of suicide attempts, life events, and suicide of others are significant suicide risk factors [54,57,61-63]. An earlier study also reported that the presence of legal/disciplinary problems, potentially fatal illnesses, persistent stress, previous self-harm, and family history of suicide are risk factors for suicidal behaviors 


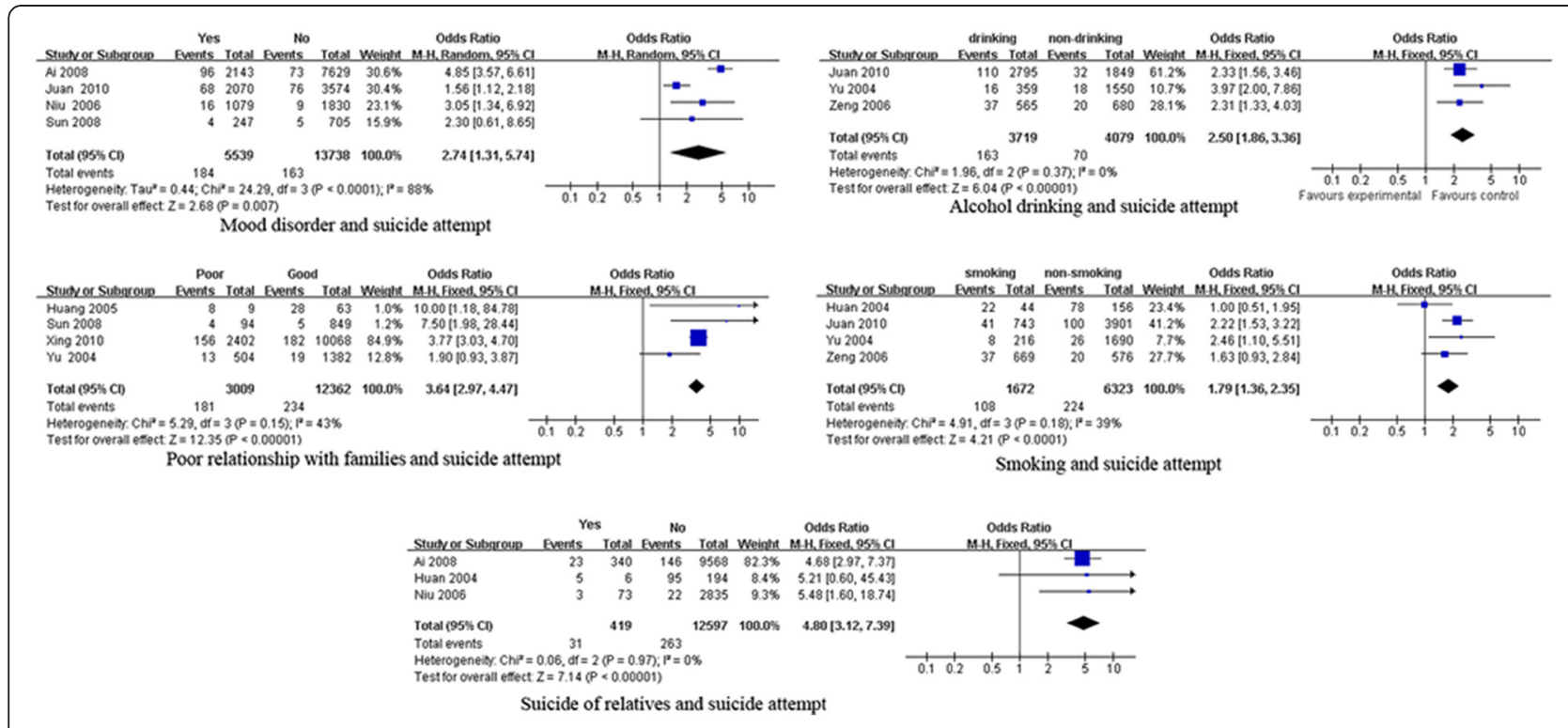

Figure 3 Forest plots of factors associated with attempted suicide. This figure shows forest plots of the meta-analysis of the association between each factor and attempted suicide. ORs and 99\% Cls for each factor are given.

$[52,55,64,65]$. Our meta-analysis indicated that people who had experienced a negative/stressful life event or a recent change in life, and those who had previously attempted suicide or had relatives/friends who had committed suicide had a higher risk of completed suicide. We also found that poor physical health and exposure to the suicide of a family member were risk factors for suicide ideation and suicide attempt. Indeed, a negative life event can trigger suicide or suicidal behavior because negative life events are associated with psychological disorders $[66,67]$.

Earlier studies have identified alcohol, smoking and drug disorders as being suicide risk factors [37,68-70]. Misuse of alcohol or drugs was also a risk factor for suicide ideation and suicide attempt [55]. Our meta-analysis similarly

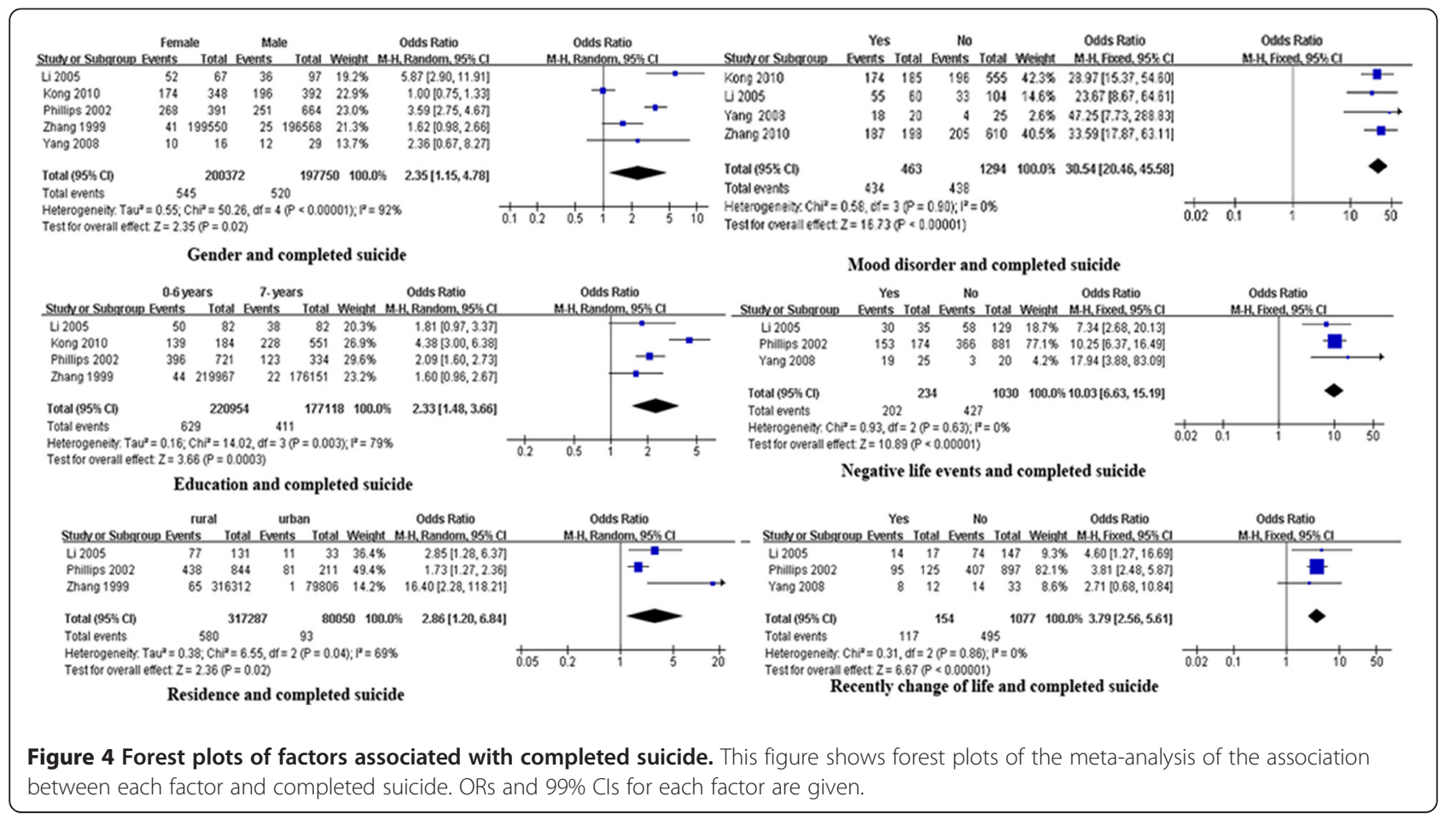



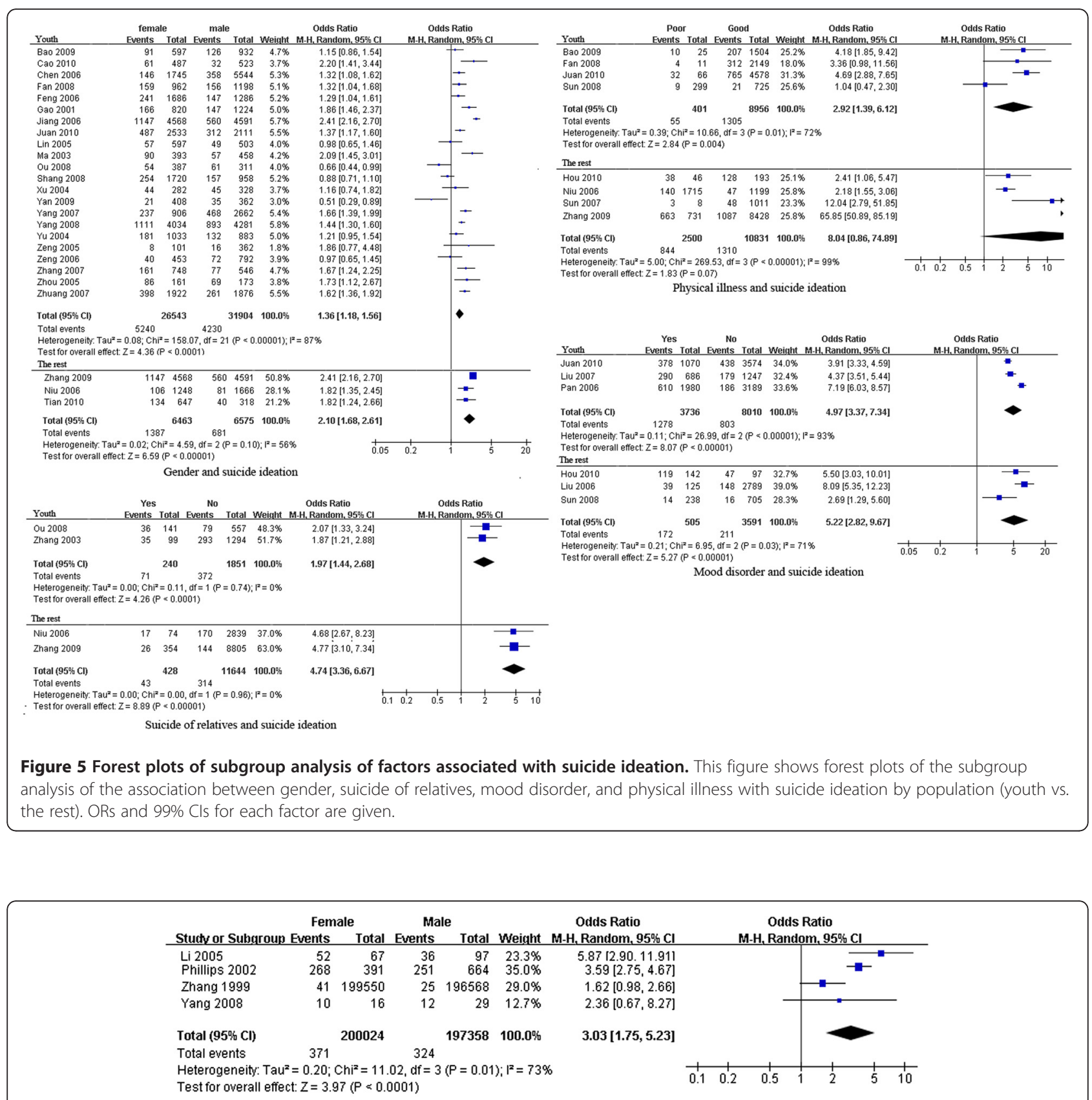

Gender and completed suicide (studies with data collected before 2000)

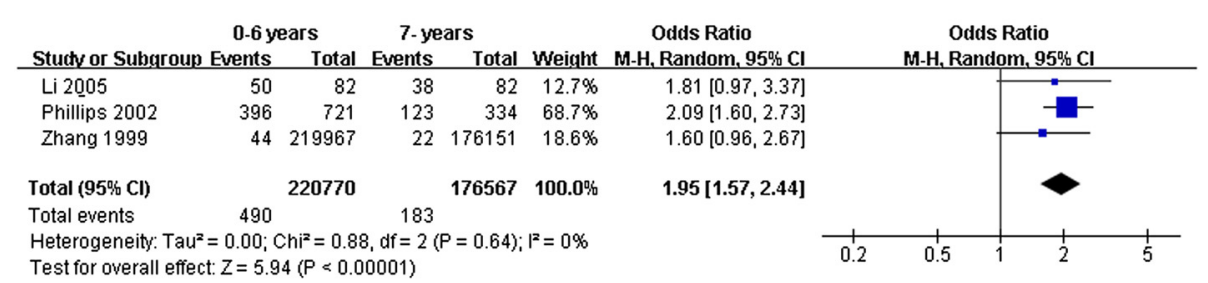

Education and completed suicide (studies with data collected before 2000)

Figure 6 Forest plots of subgroup analysis of factors associated with completed suicide. This figure shows forest plots of the subgroup analysis of the association between gender and education with completed suicide by the period of data collection (before 2000 vs. 2000 and after). ORs and $99 \% \mathrm{Cls}$ for each factor are given. 
found that among youth, smoking, alcohol use, and drug use were risk factors for suicide ideation (pooled OR= $1.67,1.96$ and 1.97, respectively), and smoking and alcohol use were risk factors for suicide attempt (pooled $\mathrm{OR}=2.03$ and 2.50 , respectively). It has long been recognized that substance abuse (alcohol and drug use) is frequently correlated with psychiatric disorders [71,72], and that smoking in youth is associated with psychiatric disorders (depression and anxiety) [73,74], which may explain how these unhealthy lifestyle behaviors increased the risk of suicidal behaviors.

Our meta-analysis also indicated that being an only child, pesticides being stored at home, a poor economy, lower social support, and seeking psychological help in hospitals were risk factors for suicide in China. However, further study is needed to confirm these risk factors because there were only a few studies of these factors included in our meta-analysis, all with small sample sizes.

This review provides a relatively comprehensive picture of risk factors for suicidality in China. However, our metaanalysis has some limitations. First, biases have been introduced because non-published data, papers without full text and papers published in languages other than English or Chinese were not included. Second, there was a lack of uniform measurement of complex socio-psychobehavioral factors among the included studies, and they covered widely different population groups, producing heterogeneity between the studies even with a subgroup analysis. Third, it is possible that the studies included in this review underestimated the association between the risk factors and suicide behaviors. Participants of studies on sensitive topics such as suicide often underreport behavior to avoid embarrassment or possible stigma [75]. Fourth, the vast majority of the included studies were cross-sectional and did not allow for inferences on causeeffect mechanisms.

Our study identified four implications for the future. First, to draw comparisons between studies of different populations and regions, it is important to emphasize the use of standardized measures of socio-psychological factors and to place adequate focus on very specific population groups in any future studies. Second, risk assessment is more necessary to identify modifiable or treatable highrisk factors and available protective factors in order to take effective countermeasures Third, most of the present studies were cross-sectional studies, therefore the future researches designed with case-control or cohort studies are needed in order to make reliable inferences on causeeffect mechanisms. Fourth, there is an urgent need to emphasize further study of interventions to prevent suicide. Intervention programs in China that simultaneously address multiple factors associated with suicide would be most appropriate since suicide is multi-factorial health problem [76].

\section{Conclusions}

In conclusion, suicide risk factors in China are very complex. People in rural areas have a higher risk of developing suicide ideation and committing suicide. Socio-family environment, psychiatric/psychological factors, lifestyle, and stressful life events are the main risk factors for suicidal behavior in China. Notably, the impact of gender on suicide is gradually decreasing. For youth, interventions should focus on changing family environments, school factors and unhealthy lifestyles.

\section{Additional file}

Additional file 1: Table S1. Quality assessment of cross-sectional studies, and Table S2. Quality assessment of case-control studies.

\section{Competing interests}

The authors declare that they have no competing interests.

\section{Authors' contributions}

JC designed the study and directed its implementation, including quality assurance and control. YiL and YaL collected, analyzed and interpreted the data; YiL draft the manuscript, JC and YaL polished the draft. All authors approved the final version for submission to BMC Public Health.

\section{Acknowledgments}

The authors thank the library of the Third Military Medical University for conducting the literature searches.

\section{Author details}

${ }^{1}$ Department of Social Medicine and Health Service Management, College of Preventive Medicine, Third Military Medical University, No.30 Gaotanyan Road, Shapingba District, Chongqing, People's Republic of China. ${ }^{2}$ Department of Epidemiology, College of Preventive Medicine, Third Military Medical University, No.30 Gaotanyan Road, Shapingba District, Chongqing, People's Republic of China. ${ }^{3}$ College of Preventive Medicine, Key Lab of Medical Protection for Electromagnetic Radiation, Ministry of Education of China, Third Military Medical University, No.30 Gaotanyan Road, Shapingba District, Chongqing, People's Republic of China.

Received: 12 March 2012 Accepted: 29 June 2012 Published: 16 July 2012

\section{References}

1. World Health Organization: Suicide rates per 100,000 by country, year and sex (Table). Geneva 27 Switzerland: World Health Organization; 2010.

2. World Health Organization: Figures and facts about suicide. Geneva; 1999. http://whqlibdoc.who.int/hq/1999/WHO_MNH_MBD_99.1.pdf. [Accessed 28 January 2011].

3. Ji J, Kleinman A, Becker AE: Suicide in contemporary China: a review of China's distinctive suicide demographics in their sociocultural context. Harv Rev Psychiatry 2001, 1:1-12.

4. Phillips MR, Li X, Zhang Y: Suicide rates in China, 1995-99. Lancet 2002, 9309:835-840.

5. Zhang J, Jing J, Wu XY, Sun WW, Wang CT: A Sociological Analysis of the Decline in the Suicide Rate in China. Social Sci China 2011, 5:97-113.

6. Zhang JX, Tang JS, Weng Z, Chai XS: Epidemiological Investigation of Suicide in Shandong Province. Chin Ment Heal J 1999, 4:248-249.

7. Kong $Y$, Zhang J: Access to farming pesticides and risk for suicide in Chinese rural young people. Psychiatry Res 2010, 2:217-221.

8. Phillips MR, Yang G, Zhang Y, Wang L, Ji H, Zhou M: Risk factors for suicide in China: a national case-control psychological autopsy study. Lancet 2002, 9347:1728-1736.

9. Li XY, Fei LP, Zhang YP, Ji HY, Xu D, Yang GH: The characteristics and risk factors for suicides with 15-24 years of age: a case-control study. Chinese J Psychiatry 2005, 4:231-235. 
10. Zhang ZQ, Guo LT: Suicide Ideas of Middle School Students. Chin Ment Heal J 2003, 12:852-855.

11. Liu RK, Wang WQ, Jia YH, Chen J, Wu TY: Risk Factors for Suicide Idea among Middle School Students in TianJin. Chinese J Pest Control 2007 11:808-810.

12. Ou GZ, Wu ZD, Xu Y: Analysis on suicide ideation and related factors among medical junior class students in Fujian Province. Chinese J Health Ed 2008, 3:167-169.

13. Ma L, Zhang JX, Wei SQ: Suicidal Ideation and Experiences of Being Bullied and Their Relationship among High School Students. Chinese J school Health 2003, 5:446.

14. Wells GA, Shea B, O'Connell D, Peterson J, Welch V, Losos M, et al: The Newcastle-Ottawa Scale (NOS) for assessing the quality of nonrandomized studies in meta-analyses. 2011, http://www.ohri. ca/ programs/clinical epidemiology/oxford.htm. [Accessed 28 January 2011].

15. Cochran BG: The combination of estimates from different experiments. Biometrics 1954, 10:101-129.

16. Higgins JP, Thompson SG: Quantifying heterogeneity in a meta-analysis. Stat Med 2002, 21:1539-1558.

17. Fan YG, Xiao Q, Li WX, Song YM, Ye QL, Ye DQ: Correlated Study between Soci-Psychological Factors and Suicide Ideation Among Medicos. Chinese J School Health 2008, 4:328-330.

18. Zhang M, Wang LG, Xing YF: Influencing Factors to Suicidal Ideation among Middle School Students. Chinese Journal of School Health 2007, 5:429.

19. Zeng LN, Chen ZY: Suicide Ideation of College Students in Guangzhou. Chinese Journal of School Health 2006, 10:863-864.

20. Li XY, Fei LP, Yang SJ, Wang ZQ, Zhang YP, Li C: Relationship of Suicide Acceptability to Self-reports of Suicidal Ideation and Behavior. Chin Ment Heal J 2009, 10:734-738.

21. Yang BS, He J, Zhong Y, Peng SP, Niang ZS: Analysis on Suicide Behaviors among the Rural Middle School Students in Henan Province. Chinese Journal of School Health 2008, 10:912-913.

22. Pan $X Q$, Shi ZM, Yuan BJ, Dai Y: Relationship between depressive mood and related risk behaviors among middle school students in Jiangsu Province. Chinese Journal of School Doctor 2006, 4:343-345.

23. Chen ZX, Yang J: Questionnaire investigation and case study on psychological crisis. China Youth Study 2006, 2:57-60.

24. Yang XH, Zhou H, Wang SM: Epidemiological Investigation of Suicidal Ideation in College Students. Chinese Journal of School Health 2007, 6:527-528.

25. Duan WD, Hu CY, Liu F, Hu JZ, Gao H, Wang J, et al: A survey on suicide idea and attempt in the parents of middle school students in Shenzhen. Medical Journal of Chinese People's Health 2008, 192:194-199.

26. Hou JL, Qin XX, Li HX, Chen W, Tang SY, Jia XJ, et al: Survey on Suicidal Ideation among Suicide Attempters of Four General Hospitals. China Modern Doctor 2010, 18:38-40.

27. Sun $X L$, Li KQ, Cun LJ, Jiang QP, Gao LH, Liu YQ, et al: The prevalence of suicide attempters in people aged 18 and older in Hebei Province. Chin Ment Heal J 2010, 5:362-365.

28. Bao DX, Fan YG, Ye DQ: Association between suicide ideation and life event and social support in College students. Chinese Journal of School Health 2009, 10:939-941.

29. Juan W, Xiao-Juan D, Jia-Ji W, Xin-Wang W, Liang X: The associations between health risk behaviors and suicidal ideation and attempts in an urban Chinese sample of adolescents. J Affect Disord 2010, 126:180-7.

30. Niu YJ, Wang ZQ, Yang SJ, Fei LP, Wang XQ: Survey of Suicidal Ideation and Suicide Attempts in Inpatients at 40 General Hospitals in Beijing. Chin Ment Heal J 2006, 7:457-461

31. Tian F, Gao J, Li YM, Cui XH, Han XL: Suicide ideation in the scientific workers in Shanxi province. Chinese Remedies \& Clinics 2010, 6:662-663.

32. Sun YH, Zhou JB, Wang B, Yu C, Yang LS: Survey of Suicidal Ideation and Suicide Attempts in the Migrant Workers in Railway Construction Sites. China Preventive Medicine 2008, 9:334-338.

33. Li GY, Tao FB, Xu L: Prevalence and Its Demographic Characteristics of Suicide Behaviors among Technical Secondary School Students. Chinese Journal of School Health 2004, 3:316-318.

34. Yu XM, Lin L, Wang J, Zhang JC, Zhao GZ: Study on self-directed violence and determinants among 1916 middle school students of the outskirts in Beijing. Chinese Journal of Reproductive Health 2004, 1:37-40.

35. Xing Y, Ji CY, Bai Y, Ji H, Wang Y: The prevalence of injuries related behaviors among middle school students in Beijing. Chinese Journal of school Health 2005, 2:114-115.
36. Gao M, Xu F, Shen QF, Zhang JX, Shao FQ, Wang BG, et al: Epidemiology of injury and mood disorder in Middle school in Hefei. Chinese Journal of School Health 2001, 3:243-244.

37. Zhuang X, Zhu XZ, Zhou YP, Lian SY, Xun PC, Jiang SY: An Epidemiological Study on Suicidal Behavior of High School Students. Chinese Journal of School Health 2007, 5:412-414.

38. Huang FY, Tao FB: Interaction Study on Drinking Alcohol and Harmful Behaviors to Health of Secondary School Students. Anhui journal of preventive medicine 2000, 1:11-13.

39. Zeng ZP, Yang Y: Risk Factors for Suicide Attempt among Medical College Students. Chinese Journal of Social Medicine 2009, 3:158-160.

40. Yan HH, Liu ZM, Wang SY, Yang G, Chen LF, Pen H, et al: Study on the relationship between life event and suicide ideation among undergraduates in Guangzhou. Modern Preventive Medicine 2009, 3:476-479.

41. Shang YX, Dong GQ, Liu T: Analysis on prevalence of suicidal ideation and depression and its influence factors among undergraduate students in Yinchuan. Chinese Journal of Public Health 2008, 8:934-936.

42. Lin Q, Xu Y: An Epidemiological Characteristic of Health Risk Behaviors Survey of Undergraduates. Acta Academiae Medicinae Suzhou 2005, 3: 432-435.

43. Zhu JP, Peng NN, Zhou YF, Gao GD, Zhu W, Luo CX: Prevalence of behaviors that contribute to unintentional and intentional injuries among college students in Shanghai. Chinese Journal of School Doctor 2006, 3:228-231.

44. Xu HL, Xiao SY, Feng SS, Chen XX: Risk factors for suicide attempt among college students at Central South University. Chinese Journal of Epidemiology 2004, 4:288-291

45. Zhou L, Xiao SY, Tang Y, Nie XQ: Suicidal ideation and its psychosocial risk factors in junior high school students in rural areas of Liuyang city. Chinese Journal of Behavioral Medical Science 2005, 12:1108-1109.

46. Jiang $\Pi$, Lu R, Zhang JX: Risk health related behavior and influencing factors in adolescents. Chinese Community Doctors 2006, 14:164-165.

47. Zhang J, Stewart R, Phillips M, Shi Q, Prince M: Pesticide exposure and suicidal ideation in rural communities in Zhejiang province, China. Bull World Health Organ 2009, 10:745-53.

48. Feng $X Y$, Huang HF, Fu YM, Li Y: Investigation on risk health related behaviors among adolescent in QingPu district of Shanghai. Chinese Journal of School Health 2006, 3:240-241.

49. Sun ML, Ye DQ, Fan YG, Pan FM: A correlation study on quality of life and suicidal ideation among rural females. Chinese Journal of Disease Control \& Prevention 2007, 2:186.

50. Huan M, Hamazaki K, Sun Y: Miho Itomura, Hongyan Liu, Wei Kang, et al: Suicide attempt and n-3 fatty acid levels in red blood cells: a case control study in China. Biol Psychiatry 2004, 7:490-6.

51. Yang CL, Liu CX, Wang RL, Yang FF, Du SQ, Zhang FG, et al: Case-control study on suicide. Practical Preventive Medicine 2008, 2:401-402.

52. Nock MK, Borges G, Bromet EJ, Cha CB, Kessler RC, Lee S, et al: Suicide and Suicidal Behavior. Epidemiol Rev 2008, 1:133-154.

53. Vijayakumar L, Pirkis J, Huong T, Yip P, De AR: Socio-economic, Cultural and Religious Factors Affecting Suicide Prevention in Asia. 2011. http://www.who. int/mental_health/resources/suicide_prevention_asia_chapter 2.pdf. [Accessed 15 February 2011].

54. Lakshmi V, Na K, Sujit J: Suicide and Suicide Prevention in Developing Countries:: Working Paper No. 27; 2011. http://www.dcp2.org/file/41/wp27. pdf [Accessed 15 February 2011].

55. Hawton K, van Heeringen K: Suicide Lancet 2009, 373:1372-81.

56. Miller M, Azrael D, Hepburn L, Hemenway D, Lippmann SJ: The association between changes in household firearm ownership and rates of suicide in the United States, 1981-2002. Injury Prevention 2006, 12:178-182.

57. King CA, Merchant CR: Social and interpersonal factors relating to adolescent suicidality: a review of the literature. Arch Suicide Res 2008, 3:181-96.

58. Hudson JL, Dodd HF, Lyneham HJ, Bovopoulous N: Temperament and family environment in the development of anxiety disorder: two-year follow-up. J Am Acad Child Adolesc Psychiatry 2011, 12:1255-64.

59. Shiang J: Does culture make a difference? Racial/ethnic patterns of completed suicide in San Francisco, CA 1987-1996 and clinical applications. Suicide and Life-Threatening Behavior 1998, 28:338-354

60. Bagge $\mathrm{CL}$, Sher KJ: Adolescent alcohol involvement and suicide attempts: toward the development of a conceptual framework. Clin Psychol Rev 2008, 8:1283-96. 
61. Wetzler S, Asnis GM, Hyman RB, Zimmerman J, Rathus JH: Characteristics of suicidality among adolescents. Suicide and Life-Threatening Behavior 1996, 26:37-45.

62. Latha KS, Bhat SM, D'Souza P: Suicide attempters in a general hospital unit in India: their socio-demographic and clinical profile-emphasis on cross-cultural aspects. Acta Psychiatr Scand 1996, 1:26-30.

63. Mann JJ: A current perspective of suicide and attempted suicide. Ann Intern Med 2002, 136:302-311.

64. Eddleston M, Sheriff MHR, Hawton K: Deliberate self-harm in Sri Lanka: an overlooked tragedy in the developing world. British Medical Journal 1998, 11(317):133-135.

65. Cheng AT, Chen TH, Chen CC, Jenkins R: Psychosocial and psychiatric risk factors for suicide. Case-control psychological autopsy study. $\mathrm{Br} J$ Psychiatry 2000, 177:360-365.

66. Hammen C: Stress and depression. Annu Rev Clin Psychol 2005, 1:293-319.

67. Paykel ES: Life events and affective disorders. Acta Psychiatr Scand 2003, 108:61-66.

68. Phillips DP, Carstensen LL: Clustering of teenage suicides after television news stories about suicide. N Engl J Med 1986, 11:685-9.

69. Gould MS: Teenage suicide clusters. JAMA 1990, 263:2051-2.

70. Rutz W, Wålinder J, Von Knorring L, Rihmer Z, Pihlgren H: Prevention of depression and suicide by education and medication: impact on male suicidality. An update from the Gotland Study International Journal of Psychiatry in Clinical Practice 1997, 1:39-46.

71. Kessler RC, Crum RM, Warner LA, Nelson CB, Schulenberg J, et al: Lifetime co-occurrence of DSM-III-R alcohol abuse and dependence with other psychiatric disorders in the National Comorbidity Survey. Arch Gen Psychiatry 1997, 4:313-21.

72. Wolitzky-Taylor K, Bobova L, Zinbarg RE, Mineka S, Craske MG: Longitudinal investigation of the impact of anxiety and mood disorders in adolescence on subsequent substance use disorder onset and vice versa. Addict Behav 2012, 37:982-5.

73. Duncan B, Rees DI: Effect of smoking on depressive symptomatology:a reexamination of data fromthe National Longitudinal Study of Adolescent Health. Am J Epidemiol 2005, 162:461-70.

74. Costello DM, Swendsen J, Rose JS, Dierker LC: Risk and protective factors associated with trajectories of depressedmood fromadolescence to early adulthood. J Consult Clin Psychol 2008, 76:173-83.

75. Johnson JG, Cohen P, Pine DS, Klein DF, Kasen S: Association between cigarette smoking and anxiety disorders during adolescence and early adulthood. JAMA 2000, 284:2348-51.

76. Phillips M: Suicide prevention in developing countries: where should we start? World Psychiatry 2004, 3:156-7.

\section{Submit your next manuscript to BioMed Central and take full advantage of:}

- Convenient online submission

- Thorough peer review

- No space constraints or color figure charges

- Immediate publication on acceptance

- Inclusion in PubMed, CAS, Scopus and Google Scholar

- Research which is freely available for redistribution 